\title{
RESEARCH AND VERIFICATION OF THE EARTH'S CRUST VELOCITY MODELS BY MATHEMATICAL SIMULATION AND ACTIVE SEISMOLOGY METHODS
}

\author{
V. V. Kovalevsky ${ }^{1}$, A. G. Fatyanov ${ }^{1}$, D. A. Karavaev ${ }^{1}$, L. P. Braginskaya ${ }^{1}$, \\ A. P. Grigoryuk ${ }^{1}$, V. V. Mordvinova ${ }^{2}$, Ts. A. Tubanov ${ }^{3}$, A. D. Bazarov ${ }^{3}$ \\ ${ }^{1}$ Institute of Computational Mathematics and Mathematical Geophysics, Siberian Branch of RAS, \\ Novosibirsk, Russia \\ ${ }^{2}$ Institute of the Earth's Crust, Siberian Branch of RAS, Irkutsk, Russia \\ ${ }^{3}$ Geological Institute, Siberian Branch of RAS, Ulan-Ude, Russia
}

\begin{abstract}
The article discusses a comparison of theoretical seismograms for two velocity models of the Earth's crust and P-wave arrival times estimated from experimental vibration seismograms for the 400-km long section of the Baikal-Ulaanbaatar profile. The theoretical seismograms were obtained by mathematical simulation of wave fields using the Earth's crust velocity models based on the data of the BEST and PASSCAL experiments. Vibration seismograms were obtained by measuring the wave field of a CVO-100 vibrator in the SB RAS Southern Baikal polygon. In the experiments, the vibration seismograms show that arrival times in the P-wave group correspond to the values for waves of large amplitudes in the theoretical seismograms. The P-wave arrival times in the theoretical seismograms of the BEST experiment are compared to the values in the experimental vibration seismograms for the $400-\mathrm{km}$ long section of the Baikal-Ulaanbaatar profile. This comparison shows that the arrival times of maximum amplitude waves correspond to the theoretical hodographs of waves with velocities of $6.25-6.80 \mathrm{~km} / \mathrm{sec}$ in the BEST experiment velocity model. At the same time, the experimental data set does not contain arrival times corresponding to longitudinal waves with $\mathrm{Vp}=7.25 \mathrm{~km} / \mathrm{sec}$, which are related to an assumed layer (more than $10 \mathrm{~km}$ thick) in the lower crust for the BEST experiment velocity model. In the experiments, the P-wave arrival times in the vibration seismograms correspond to the P-wave arrival times in the theoretical seismograms of the PASSCAL experiment throughout the entire $400-\mathrm{km}$ long section of the Baikal-Ulaanbaatar profile. It is thus confirmed that the average values of the wave velocities in the PASSCAL velocity model have been reliably estimated. It should be noted that the experimental values of the arrival times of the first wave in the P-wave group are in agreement with the first arrival times in the hodographs of the theoretical seismograms for the velocity model in the PASSCAL experiment considering the distances from the source in a range of $65-380 \mathrm{~km}$.
\end{abstract}

Key words: Earth's crust velocity model; verification; BEST and PASSCAL experiments; theoretical seismogram; vibroseismic investigation

Статья публикуется по материалам доклада, сделанного авторами на XII Российско-Монгольской международной конференции «Солнечно-земные связи и геодинамика Байкало-Монгольского региона» (1-5 октября 2018 г., г. Иркутск)

RESEARCH ARTICLE

Received: February 5, 2019

Revised: June 21, 2019

Accepted: July 2, 2019

For citation: Kovalevsky V.V., Fatyanov A.G., Karavaev D.A., Braginskaya L.P., Grigoryuk A.P., Mordvinova V.V., Tubanov Ts.A., Bazarov A.D., 2019. Research and verification of the Earth's crust velocity models by mathematical simulation and active seismology methods. Geodynamics \& Tectonophysics 10 (3), 569-583. doi:10.5800/GT-2019-10-3-0427. 


\title{
ИССЛЕДОВАНИЕ И ВЕРИФИКАЦИЯ СКОРОСТНЫХ МОДЕЛЕЙ ЗЕМНОЙ КОРЫ МЕТОДАМИ МАТЕМАТИЧЕСКОГО МОДЕЛИРОВАНИЯ И АКТИВНОЙ СЕЙСМОЛОГИИ
}

\author{
В. В. Ковалевский 1 , А. Г. Фатьянов ${ }^{1}$, Д. А. Караваев ${ }^{1}$, Л. П. Брагинская ${ }^{1}$, \\ А. П. Григорюк ${ }^{1}$, В. В. Мордвинова², Ц. А. Тубанов ${ }^{3}$, А. Д. Базаров 3 \\ ${ }^{1}$ Институт вычислительной математики и математической геофизики СО РАН, \\ Новосибирск, Россия \\ ${ }^{2}$ Институт земной коры СО РАН, Иркутск, Россия \\ ${ }^{3}$ Геологический институт СО РАН, Улан-Удэ, Россия
}

\begin{abstract}
Аннотация: Представлены результаты сравнения теоретических сейсмограмм для двух скоростных моделей земной коры и данных о временах вступлений Р-волн на экспериментальных вибрационных сейсмограммах на 400-километровом участке профиля Байкал - Улан-Батор. Теоретические сейсмограммы получены методами математического моделирования волновых полей для скоростных моделей земной коры, построенных по данным экспериментов BEST и PASSCAL. Вибрационные сейсмограммы получены при измерении волнового поля вибратора ЦВО-100 Южно-Байкальского полигона СО РАН. Экспериментальные значения времен вступлений в группе Р-волн на вибрационных сейсмограммах соответствуют значениям на теоретических сейсмограммах для волн большой амплитуды. Сравнение теоретических сейсмограмм эксперимента BEST и данных о временах вступлений Р-волн на экспериментальных вибрационных сейсмограммах на 400-километровом участке профиля Байкал - Улан-Батор показывает, что экспериментальные времена вступлений волн максимальной амплитуды соответствуют теоретическим годографам волн со скоростью 6.25-6.80 км/с скоростной модели эксперимента BEST. Вместе с тем экспериментальные данные не содержат времен вступлений, соответствующих продольным волнам со скоростью Vp=7.25 км/с, связанных с предполагаемым слоем мощностью более 10 км в нижней коре в скоростной модели эксперимента BEST. Экспериментальные значения времен вступлений волн в группе Р-волн вибрационных сейсмограмм находятся в области времен вступлений волн на теоретических сейсмограммах эксперимента PASSCAL на всем протяжении 400-километрового профиля. Это свидетельствует о надежном определении средних значений скоростей волн в скоростной модели эксперимента PASSCAL. Следует отметить, что экспериментальные значения времен вступлений первой волны в группе Р-волн согласуются с временами первых вступлений на годографах теоретических сейсмограмм для скоростной модели эксперимента PASSCAL в диапазоне расстояний от 65 до 380 км от источника.
\end{abstract}

Ключевые слова: скоростная модель земной коры; верификация; эксперименты BEST и PASSCAL; теоретическая сейсмограмма; вибросейсмическое исследование

\section{1. ВВЕДЕНИЕ}

Исследования строения земной коры Байкальской рифтовой зоны (БРЗ) и сопредельных территорий связаны с изучением процессов рифтогенеза и современной геотектоники в самой большой по протяженности и наиболее сейсмически активной континентальной рифтовой зоне Евразии.

Основные результаты в построении скоростных моделей земной коры БРЗ и прилегающей к ней Сибирской платформы с севера и Саяно-Байкальской складчатой области с юга и юго-востока были получены методом глубинного сейсмического зондирования (ГСЗ). Были определены глубины границы Мохоровичича и скорости продольных волн в верхней мантии под подошвой земной коры БРЗ [Puzyrev, 1981; Mishen'kin et al., 1999; Seleznev et al.,
2003; Suvorov et al., 2002]. Результаты обработки данных ГСЗ показали истончение земной коры до 34-36 км под южным и центральным бассейнами БРЗ и пониженные значения скорости продольных волн под корой - 7.7-7.8 км/с. В прилегающих к БРЗ территориях толщина земной коры была оценена в 37-40 км под Сибирской платформой и не менее 50 км под Саяно-Байкальской складчатой областью. Оценки скорости продольных волн под подошвой земной коры под соседними Сибирской платформой и Саяно-Байкальским складчатым поясом составляют 8.1-8.2 км/с [Puzyrev et al., 1973, 1978; Krylov et al., 1974; Puzyrev, 1981; Zorin et al., 1989, 2002, 2003]. B исследованиях [Suvorov et al., 2002] на основе обработки данных ГСЗ определены изменения толщины земной коры в регионе от 35 до 50 км, но не выявлено утончения земной коры под БРЗ. 
По результатам работ ГСЗ на акватории Байкала для центрального бассейна БРЗ была построена скоростная модель с глубиной границы Мохо 39-43 км, с высокоскоростным (7.05-7.40 км/с) слоем в нижней коре мощностью 8 км и нормальной скоростью продольных волн 8 км/с в верхней мантии под корой [Ten Brink, Taylor, 2002]. Такой же вывод о наличии высокоскоростного слоя в нижней коре южного бассейна был сделан по результатам подробного профиля ГСЗ эксперимента BEST [Nielsen, Thybo, 2009]. В построенной скоростной модели земной коры высокоскоростной слой в нижней коре мощностью 10-14 км простирается под Сибирской платформой, БРЗ и Саяно-Байкальской складчатой областью. Скорость продольных волн в этом слое 7.2-7.3 км/с вне БРЗ, в слое в нижней коре под рифтом имеется высокоскоростная аномалия (7.47.9 км/с). Скорость продольных волн под подошвой земной коры на всем протяжении слоя оценена в $8.15-8.20 \mathrm{\kappa м} / \mathrm{c}$.

Для построения скоростных моделей земной коры в БРЗ наряду с методом ГСЗ применяется метод приемной функции, предложенный и развитый в работах [Vinnik, 1977; Burdick, Langston, 1977; Owens et al., 1984; Ammon et al., 1990; Kosarev et al., 1993; Gao et al., 2004]. Метод основан на регистрации телесейсмических событий (землетрясений) с большой магнитудой с эпицентральными расстояниями до 10000 км, что обеспечивает близкий к вертикальному выход Р-волн на регистрирующую станцию. Построение скоростной модели коры под станцией основано на анализе вступлений в коде Р-волны обменных поперечных волн. В южной части БРЗ проведено несколько профильных наблюдений по методу приемной функции [Mordvinova et al., 1995, $2000,2007]$. Построенные по данным наблюдательного эксперимента PASSCAL [Mordvinova, Artemyev, 2010] скоростные модели имеют слабовыраженную слоистую структуру в виде мозаики отдельных блоков. Толщина земной коры под Сибирской платформой и БР3 37-38 км, под Саяно-Байкальским складчатым поясом - 45-50 км с локальным утолщением под хребтом Хамар-Дабан. Скорость поперечных волн в земной коре вблизи подошвы $3.9-4.0$ км/с, в верхней мантии под земной корой $4.3-4.5 \mathrm{\kappa m} / \mathrm{c}$.

\section{2. МЕТОДИКА ИССЛЕДОВАНИЯ И ВЕРИФИКАЦИИ СКОРОСТНЫХ МОДЕЛЕЙ ЗЕМНОЙ КОРЫ}

Следует отметить, что скоростные модели земной коры БРЗ и окружающих ее тектонических районов противоречивы. При этом даже для одного и того же профиля наблюдений скоростные модели земной коры, построенные с применением метода
ГСЗ (эксперимент BEST) и метода приемной функции (эксперимент PASSCAL), имеют существенные различия, как качественные - в характерном виде выделяемых структур, так и количественные - в значениях распределения скоростей продольных и поперечных волн [Nielsen, Thybo, 2009; Mordvinova, Artemyev, 2010]. Это обусловлено различием применяемых методов и характеристик используемых источников сейсмических волн - взрывов и землетрясений.

Сравнение различных скоростных моделей земной коры ставит задачу их верификации и проверки представленных моделей независимыми методами, как теоретическими, так и экспериментальными. При теоретическом подходе каждая рассматриваемая скоростная модель земной коры позволяет рассчитать теоретические сейсмограммы от поверхностного источника сейсмических волн с регистрацией в выбранных точках наблюдения. Эти теоретические сейсмограммы необходимо сравнить с экспериментальными сейсмограммами, полученными от прецизионного сейсмического источника, имеющего точно известные и контролируемые характеристики излучения сейсмических волн.

В работах [Kovalevsky et al., 2016a, 2016b, 2017] была предложена методика исследования и верификации скоростных моделей земной коры на основе применения математического моделирования и методов активной сейсмологии, основанной на использовании мощных сейсмических вибраторов в качестве прецизионных источников сейсмических волн [Alekseev et al., 1997, 2005; Tsibulchik, 2004.]. Эта методика применялась для исследования и верификации двух скоростных моделей земной коры, полученных для юга Байкальской рифтовой зоны и сопредельных областей Монголии в экспериментах BEST и PASSCAL (рис. 1). Для верификации построенных моделей определялось соответствие рассчитанных для них теоретических сейсмограмм реально регистрируемым сейсмограммам на выбранном участке профиля. В качестве экспериментальных сейсмограмм использовались данные вибросейсмических зондирований, выполненных ИВМиМГ СО РАН и ГИН СО РАН в 2011-2013 гг. на 500-километровом профиле Байкал - Улан-Батор с использованием мощного сейсмического вибратора Южно-Байкальского полигона.

\section{3. МАТЕМАТИЧЕСКОЕ МОДЕЛИРОВАНИЕ ПОЛНЫХ ВОЛНОВЫХ ПОЛЕЙ ДЛЯ СКОРОСТНЫХ МОДЕЛЕЙ ЗЕМНОЙ КОРЫ ЭКСПЕРИМЕНТОВ ВЕST И PASSCAL}

Международный проект BEST (Baikal Explosion Seismic Transect) был выполнен в 2002 г. учеными 


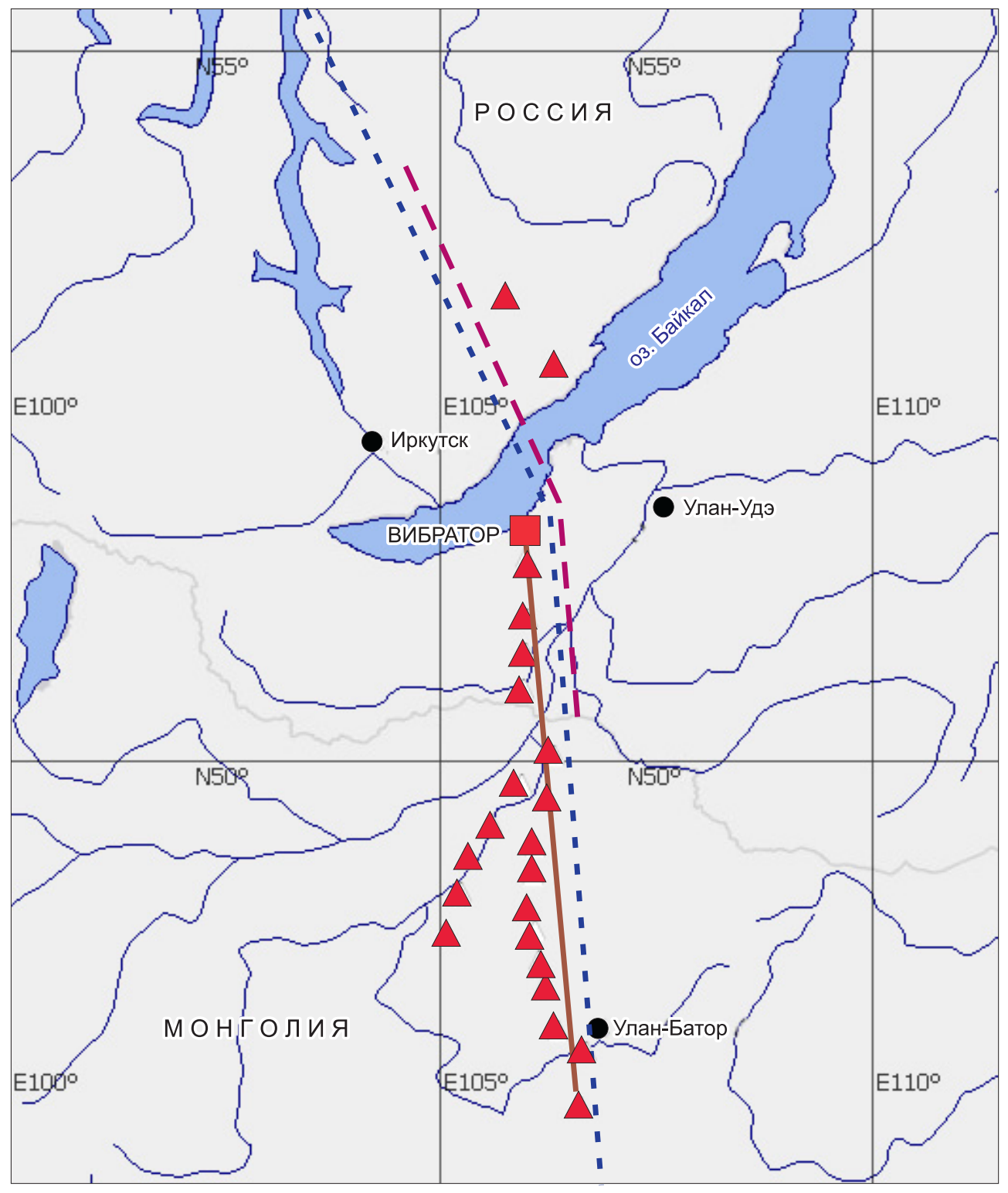

Рис. 1. Карта южной части Байкальского региона и Северной Монголии с профилями регистрации сейсмических данных. Профиль эксперимента BEST - пунктирная линия, профиль эксперимента PASSCAL - точечная линия, 500-километровый профиль вибро-ГСЗ Байкал-Улан-Батор - сплошная линия. Точки регистрации вибросигналов на профиле вибро-ГСЗ отмечены треугольниками, вибратор - черным кругом.

Fig. 1. Map of the southern part of the Baikal region and northern Mongolia. Seismic data recording profiles: BEST experiment - dashed line; PASSCAL experiment - dotted line; Baikal-Ulaanbaatar vibro-DSS profile (500 km long) - solid line. Triangles - vibroseismic signal record points on the vibro-DSS profile; black circle - vibrator.

Сибирского отделения РАН, Копенгагенского университета, Дания, и Польской академии наук. Целью проекта являлось определение скоростного строения земной коры и верхней мантии под южной границей Сибирской платформы, Байкалом и Саяно-Байкальским складчатым поясом. Сейсмические данные были получены по методике глубинного сейсмического зондирования с отраженными и преломленными волнами на 360-километровом профиле, пересекающем Байкал и основные тектонические структуры Южного Байкала. Использова- лись 175 цифровых регистраторов, установленных вдоль профиля с шагом 2 км. В качестве сейсмических источников использовались 10 взрывов от 500 до 2500 кг взрывчатки в тротиловом эквиваленте, которые проводились в 50-метровых скважинах на суше, а также воздушные пушки на акватории Байкала и частично свип-сигналы сейсмического вибратора ЦВО-100 Южно-Байкальского полигона. По результатам обработки зарегистрированных сейсмограмм была построена 2D-модель скоростей сейсмических волн в земной коре вдоль 

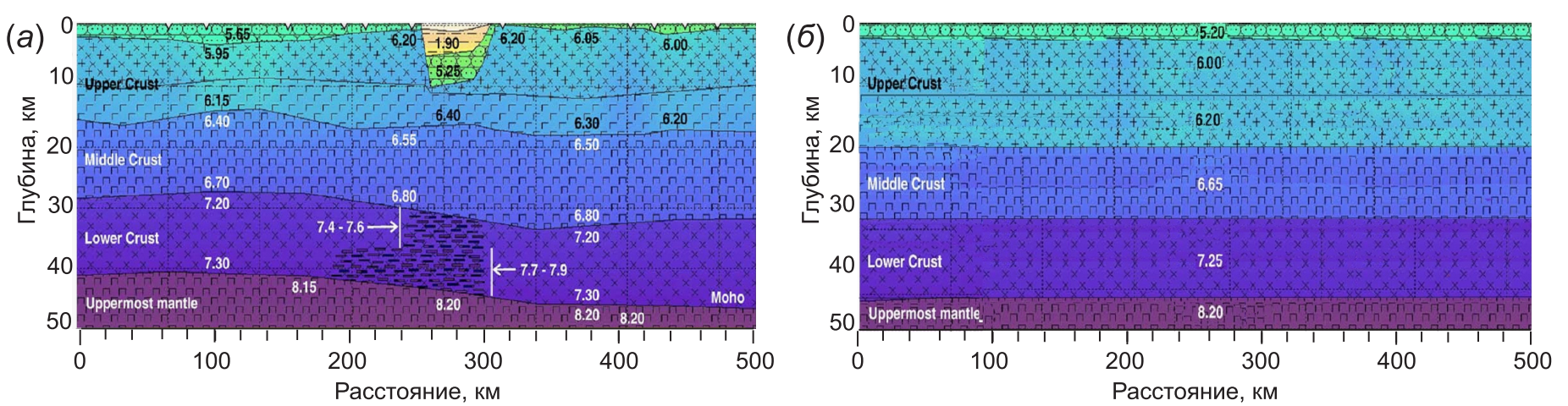

Рис. 2. Скоростная модель земной коры по результатам эксперимента BEST [Nielsen,Thybo, 2009] (a). Математическая модель с пятью горизонтальными слоями в земной коре для расчета полного волнового поля на профиле Байкал-Улан-Батор (б). Цифрами указаны значения скоростей продольных волн Vp, км/с.

Fig. 2. The Earth's crust velocity model based on the data of the BEST experiment [Nielsen, Thybo, 2009] (a). Mathematical model including five horizontal layers in the crust; this model was used to calculate the complete wave field on the BaikalUlaanbaatar profile (б). Numbers - P-waves velocities (Vp, km/s).

360-километрового профиля, пересекающего Байкал [Nielsen, Thybo, 2009]. В скоростной модели выделены пять слоев (рис. 2). В нижней коре на границе с мантией под Байкалом выделяется зона повышенных скоростей от 7.4-7.6 до 7.7-7.9 км/с на глубинах от 30 до 40 км. Второй особенностью модели является наличие высокоскоростного слоя со скоростью 7.2-7.3 км/с мощностью более 10 км на глубине от 28 до 42 км под Сибирской платформой и на глубине от 32 до 46 км под Саяно-Байкальским складчатым поясом в Южном Прибайкалье.

Для математического моделирования и расчета полного волнового поля на профиле Байкал - УланБатор была построена математическая модель скоростной структуры земной коры по данным эксперимента BEST (рис. 2). Модель включает пять слоев со следующими скоростями Р-волн и мощностями: 1-й слой 5.20 км/с, 1 км, 2-й слой 6.00 км/с, 9 км, 3-й слой 6.20 км/с, 8 км, 4-й слой 6.65 км/с, 14 км, 5-й слой 7.25 км/с, 14 км. Последний слой на глубине 46 км граничит с мантией, имеющей скорость Р-волн 8.20 км/с. Средняя толщина и средняя скорость Р-волн в слоях совпадают с исходной скоростной моделью из [Nielsen, Thybo, 2009] в части, относящейся к Саяно-Байкальской складчатой области. В математической модели слои имеют горизонтальные границы, что дает возможность применения численно-аналитических методов при математическом моделировании.

Вторая скоростная модель земной коры для этого района построена по результатам российскоамериканского телесейсмического эксперимента PASSCAL (Program for the Array Seismic Study of Continental Lithosphere), который проводился в 1991-1992 гг. на юге Сибирской платформы, в юж- ной части Байкальской рифтовой зоны и на территории Монголии с использованием 46 цифровых станций, установленных на расстоянии 20-50 км друг от друга, с максимальной длиной профиля 1000 км. Было зарегистрировано и обработано более 100 сейсмограмм телесейсмических событий (землетрясений) с магнитудой более 5.5 , с эпицентральными расстояниями 30-80 (3500-9000 км). Анализ сейсмограмм производился методом приемной функции с выделением из коды Р-волны приемных SV-функций [Vinnik, 1977]. Восстановление S- и Р- скоростных разрезов на базе выделенных продольных приемных функций осуществлялось согласно алгоритму Г.Л. Косарева [Kosarev et $a l ., 1993]$. По результатам экспериментов построена 2D-модель скоростей поперечных сейсмических волн в земной коре для 1000-километрового профиля [Mordvinova, Artemyev, 2010] (рис. 3). Скоростная модель имеет слабовыраженную слоистую структуру. Границы слоев характеризуются сильной изменчивостью (особенно под озером Байкал и примыкающими горами Хамар-Дабана), имеются также пятнистые включения зон повышенных и пониженных скоростей сейсмических волн.

Математическая модель скоростной модели земной коры эксперимента PASSCAL для профиля Байкал - Улан-Батор была построена путем сплайновой интерполяции скоростных разрезов профильных станций по данным [Mordvinova, Artemyev, 2010] (рис. 3). Скорости продольных волн вычислялись по значениям скоростей поперечных волн в предположении постоянного отношения $\mathrm{Vp} / \mathrm{Vs}=1.73$ для земной коры и $\mathrm{Vp} / \mathrm{Vs}=1.8$ для мантии. Для математического моделирования применялись конечно-разностные методы расчета полного волнового поля. 

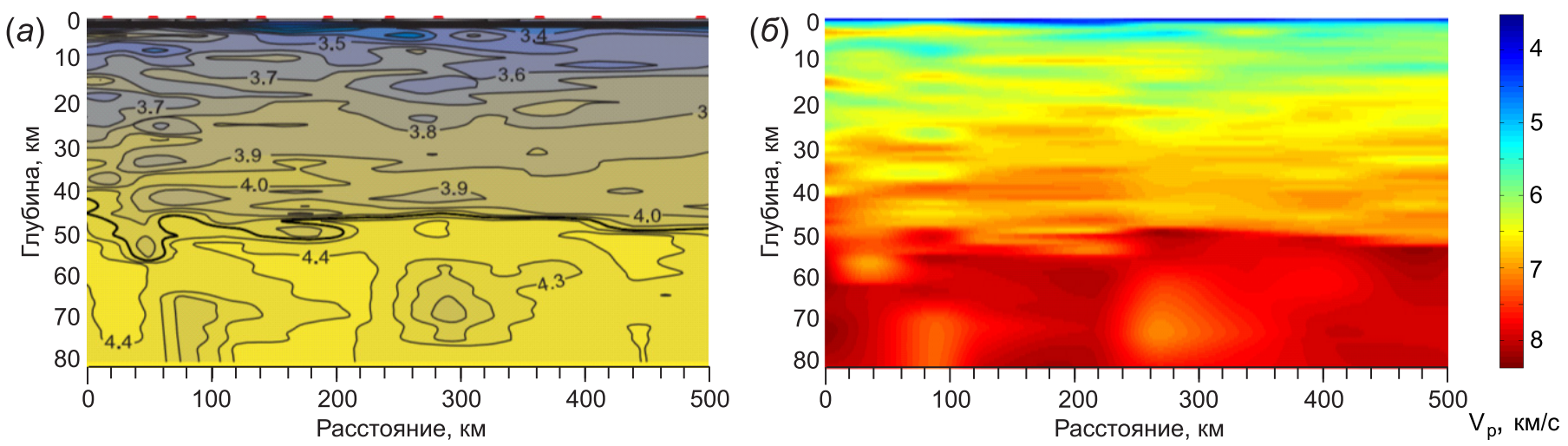

Рис. 3. Скоростная модель земной коры для профиля Байкал - Улан-Батор по результатам эксперимента PASSCAL [Mordvinova, Artemyev, 2010] (a). На изолиниях указаны значения скоростей поперечных волн, км/с. Математическая модель, полученная сплайновой интерполяцией данных эксперимента PASSCAL для расчета полного волнового поля на профиле Байкал - Улан-Батор (б), цветовая шкала - скорость продольных волн Vp, км/с.

Fig. 3. The Earth's crust velocity model for the Baikal - Ulaanbaatar profile, based on the data of the PASSCAL experiment [Mordvinova, Artemyev, 2010] (a). Number on isolines - S-waves velocities (Vs, km/sec). Mathematical model resulting from spline interpolation of the PASSCAL experiment data; this model was used to calculate the complete wave field on the Baikal - Ulaanbaatar profile (б). Colour codes - P-waves velocities (Vp, km/sec).

Математическое моделирование полных волновых полей для представленных математических моделей земной коры было выполнено с применением алгоритмов и программ, разработанных в ИВМиМГ СО РАН для решения задач динамической теории упругости сложнопостроенных сред.

Расчет полного волнового поля для скоростной модели земной коры эксперимента BEST (cм. рис. 2) выполнен с применением модифицированного численно-аналитического метода для плоскослоистых 3D-моделей сред. Метод позволяет проводить «безартефактные» расчеты на сверхдальние расстояния на профилях большой протяженности. В методе используются аналитические преобразования по пространственной и временной переменной и численно вычисляются значений рядов аналитических функций [Fatyanov, 1990; Fatyanov, Terekhov, 2011]. Важной особенностью метода является получение точного аналитического решения для больших размеров расчетной области, что имеет принципиальное значение для получения сейсмограмм для скоростных моделей земной коры протяженностью несколько сотен километров.

Математическое моделирование полного вибросейсмического поля для существенно неоднородной 2D-модели скоростей сейсмических волн в земной коре по данным эксперимента PASSCAL (рис. 3) было выполнено в Сибирском суперкомпьютерном центре с использованием гибридных многоядерных вычислительных систем с графическими ускорителями (GPU). Использовались параллельные алгоритмы на основе конечно-разностных методов и разработанная модифицированная ко- нечно-разностная схема четвертого порядка точности по пространству. Для исключения отражений упругих волн от границ расчетной области использовался метод поглощающих границ для выбранной разностной схемы [Karavaev, 2009; Karavaev et al., 2015].

В результате математического моделирования волновых полей для математических скоростных моделей земной коры, построенных по данным экспериментов BEST и PASSCAL, получены теоретические сейсмограммы для расстояний 0-400 км от источника (рис. 4). Теоретические сейсмограммы экспериментов существенно отличаются друг от друга.

На теоретических сейсмограммах для слоистой скоростной модели эксперимента BEST (рис. 4, a) отчетливо выделяются прямые, отраженные, преломленные волны с временами вступлений и скоростями, соответствующими слоям модели. Цифрами отмечены следующие группы волн: 1 - поверхностные и поперечные волны со скоростью 3.40 км/с и менее; 2 - прямая волна, распространяющаяся по верхнему слою со скоростью 5.15 км/с; 3 - волны в первых вступлениях на расстояниях 0-125 км с характерной скоростью 6.06 км/с; 4-6 волны с закритическими отражениями в трех нижних слоях земной коры с характерной скоростью 6.25 км/с (4), 6.70-6.80 км/с (5), 7.33-7.46 км/с (6); 7 - рефрагированная от мантии волна малой амплитуды со скоростью около 8.20 км/с. Годографы первых вступлений характеризуются следующими скоростями: на расстояниях 0-125 км - 6.06 км/с, на расстояниях $125-230$ км - 6.64 км/с, на расстоя- 

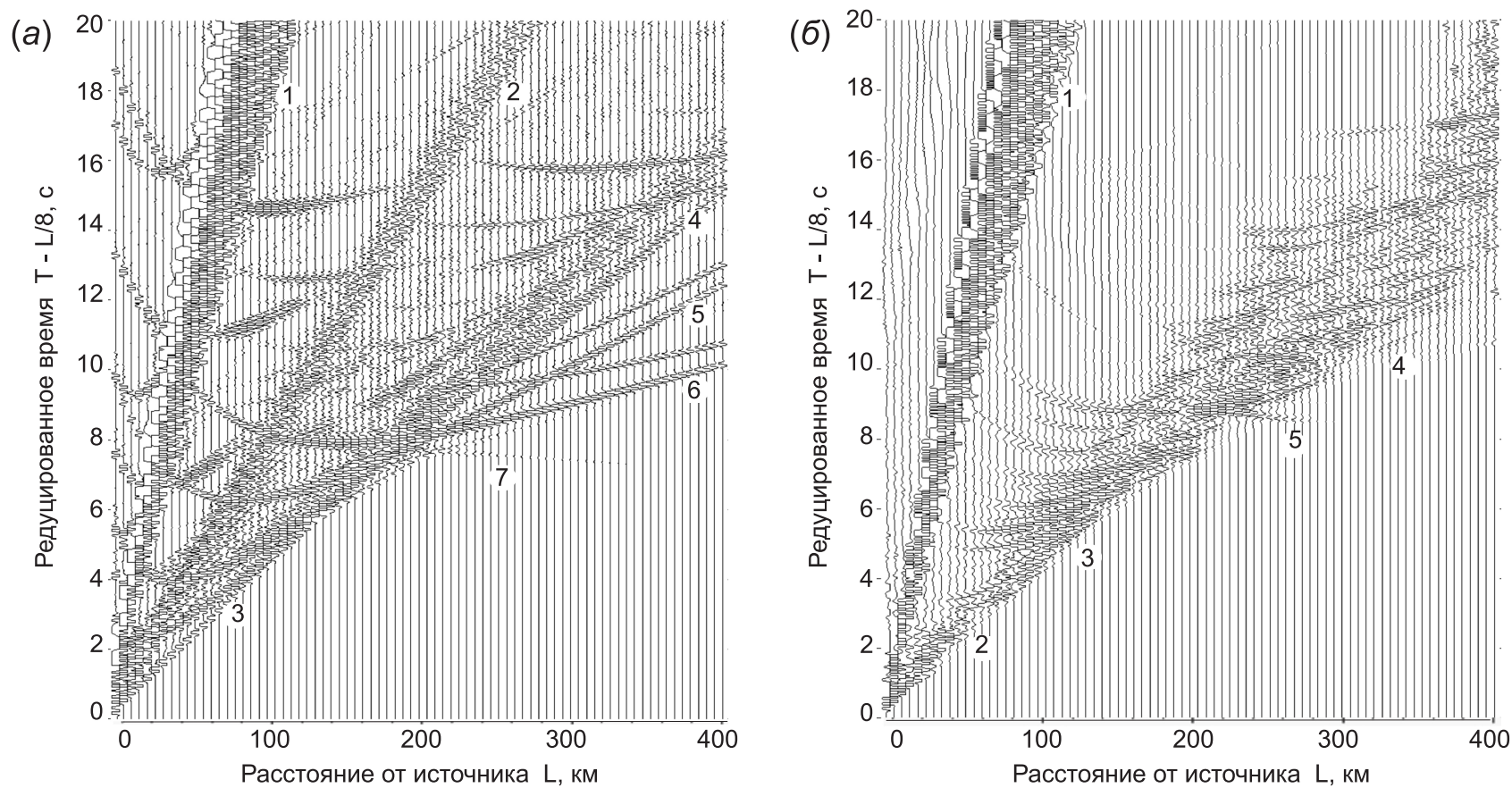

Рис. 4. Редуцированные теоретические сейсмограммы для 400-километрового участка профиля Байкал - УланБатор для математических скоростных моделей земной коры, построенных по данным эксперимента BEST (a) и эксперимента PASSCAL (б). Скорость редукции 8 км/с. На графиках цифрами отмечены группы волн на различных расстояниях от источника (пояснение в тексте).

Fig. 4. Reduced theoretical seismograms for the 400-km long section of the Baikal-Ulaanbaatar profile for the mathematical velocity models of the crust based on the BEST and PASSCAL experiment data: (a) and (б), respectively. The reduction velocity is $8 \mathrm{~km} / \mathrm{sec}$. Numbers on the graphs - groups of waves at various distances from the source (explained in the text).

ниях 230-400 км - 7.33 км/с. Рефрагированная волна, распространяющаяся по верхней мантии со скоростью 8.20 км/с, имеет малую амплитуду и прослеживается на теоретических сейсмограммах с расстояний 205 км. Значения скоростей в группах волн и в первых вступлениях определены приблизительно из графиков рис. 4.

Теоретические сейсмограммы для неоднородной скоростной модели эксперимента PASSCAL (рис. 4, б) имеют вид протяженных групп колебаний, представляющих суперпозицию волн с областями прослеживания 50-100 км. Длительность колебаний в группе вступлений Р-волн возрастает с расстоянием от 1-2 с на расстояниях 0-50 км до 4-6 с на расстояниях 300-400 км. Цифрами отмечены следующие группы волн: 1 - поверхностные и поперечные волны со скоростями от 2.31 до 3.43 км/с; 2 - группа волн на расстояниях 0-60 км, представленная прямыми и отраженными от близких к поверхности слоев волнами, характерной кажущейся скоростью, определенной по первым вступлениям 6.00-6.10 км/с; 3 - группа волн на расстояниях 60-160 км, в которых отчетливо проявляются волны, отраженные от внутренних слоев коры; 4 - группа волн на расстояниях 200-400 км с областями прослеживания 60-100 км, в которой волны малой амплитуды в первых вступлениях имеют кажущуюся скорость 6.94 км/с; 5 - рефрагированная волна, распространяющаяся по верхней мантии, с кажущейся скоростью 8.20-8.30 км/с, которая имеет малую амплитуду на теоретических сейсмограммах и прослеживается на расстояниях 220-250 км.

\section{4. ВИБРОСЕЙСМИЧЕСКИЕ ИССЛЕДОВАНИЯ НА 500- КИЛОМЕТРОВОМ ПРОФИЛЕ БАЙКАЛ - УЛАН-БАТОР}

Экспериментальные работы по активной сейсмологии проводятся в Южном Прибайкалье с использованием в качестве источника сейсмических волн мощного 100-тонного сейсмического вибратора ЦВО-100 (рис. 5), расположенного на Южнобайкальском геодинамическом полигоне СО РАН [Tat'kov et al., 2013; Kovalevskiy et al., 2017]. Целью работ является глубинное вибросейсмическое зондирование земной коры (вибро-ГСЗ) в зоне сочленения Сибирской платформы, БРЗ и Саяно-Байкальской складчатой области.

Сейсмический вибратор ЦВО-100, установленный на Южно-Байкальском полигоне возле п. Бабушкин, развивает вибрационные усилия на грунт 


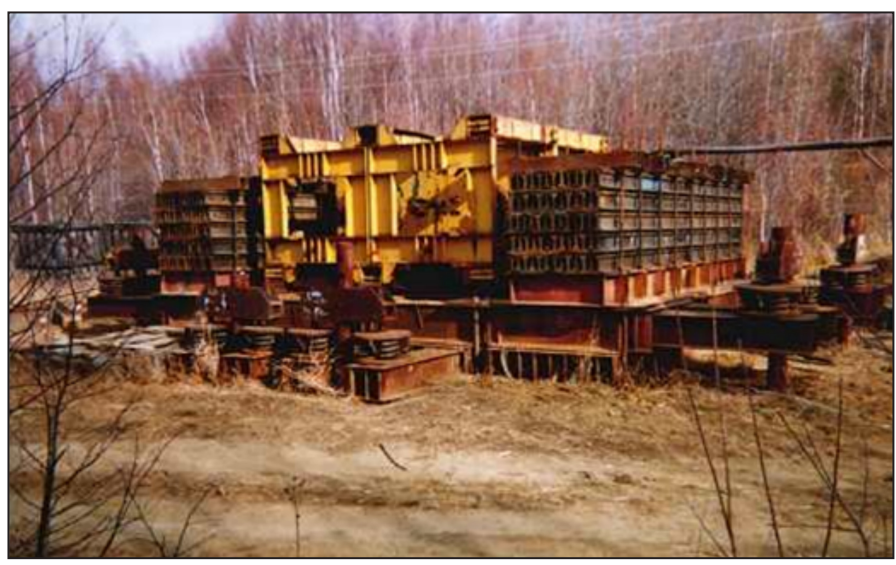

100 т в диапазоне частот 5-12 Гц и может работать в режиме излучения свип-сигналов с линейно изменяющейся частотой по времени и гармонических сигналов с постоянной частотой. В работах на профиле Байкал - Улан-Батор использовались вибрационные свип-сигналы длительностью 3264 с с линейной разверткой частоты от 6.25 до 10.05 Гц. Излученные свип-сигналы вибратора характеризуются высокой повторяемостью. На рис. 6 приведена автокорреляционная функция единичного излученного свип-сигнала, а также автокорреляционные функции и спектры серии из десяти свипсигналов.
Pис. 5. Сейсмический вибратор ЦВО-100 с вибрационным усилием 100 тс и частотным диапазоном 5-12 Гц. Южно-Байкальский полигон СО РАН, п. Бабушкин.

Fig. 5. CVO-100 seismic vibrator. Vibration force - 100 tonnes; frequency range - 5-12 Hz. Southern Baikal polygon, Babushkin settlement.
В 2011-2013 гг. на 500-километровом профиле Байкал - Улан-Батор были выполнены работы по вибрационному глубинному сейсмическому зондированию (вибро-ГСЗ) [Kovalevskiy et al., 2017]. Точки регистрации располагались на профиле от 65 до 500 км от источника ЦВО-100, расстояние между точками регистрации составляло от 20 до 50 км (см. рис. 1). В каждой точке регистрации использовались малые сейсмические группы из 5-10 трехкомпонентных датчиков с цифровыми регистраторами «Байкал». Датчики располагались линейно с направлением компоненты X на вибратор. Расстояние между датчиками было 200 м, общая база
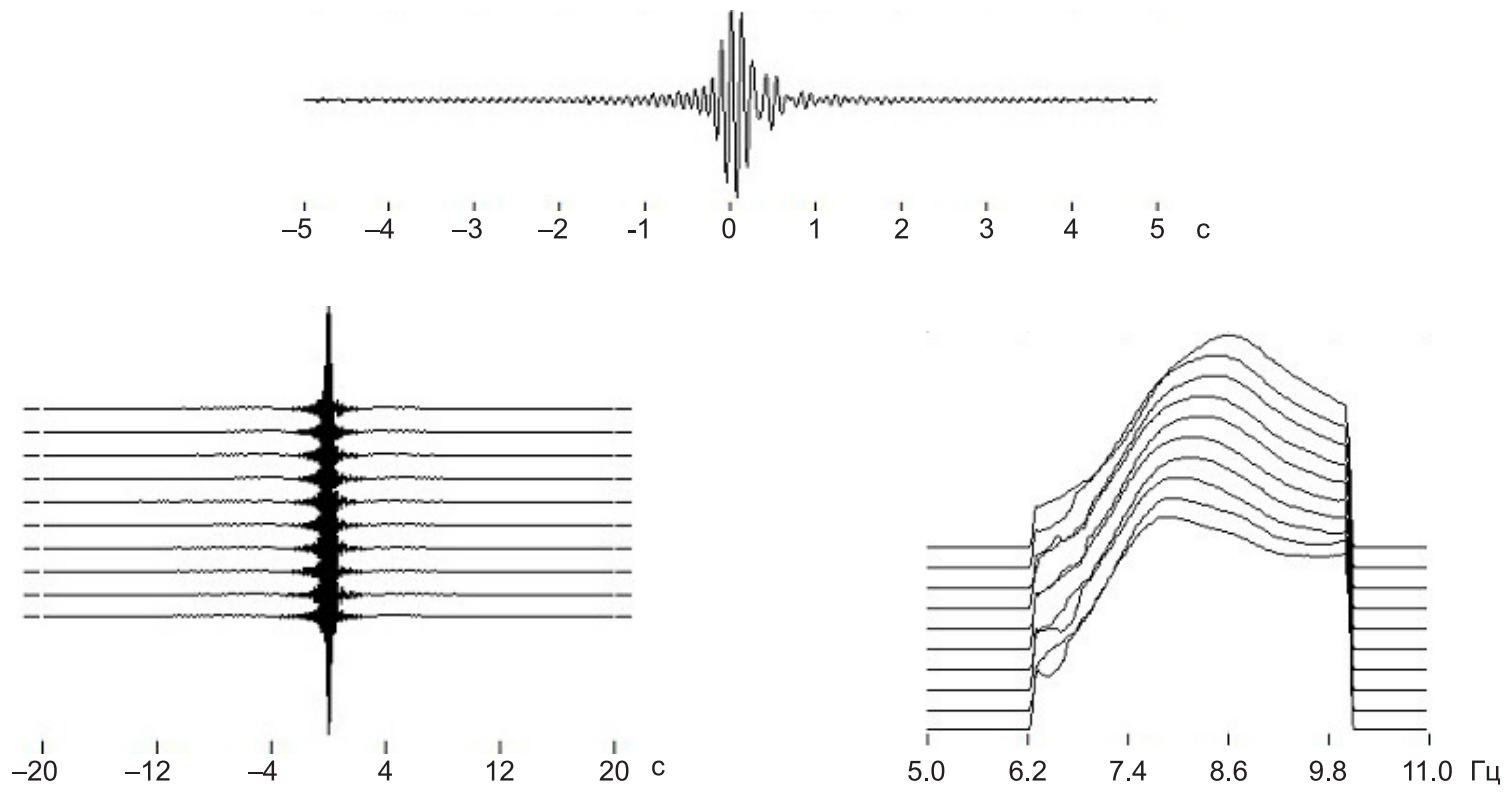

Рис. 6. Автокорреляционная функция свип-сигнала 6.25-10.05 Гц (на верхнем блоке, по горизонтали - время, с). Автокорреляционные функции серии из десяти излученных свип-сигналов (внизу слева, по горизонтали - время, с) и их спектры (на нижнем блоке, справа, по горизонтали частота, Гц).

Fig. 6. Autocorrelation function of 6.25-10.05 Hz sweep signal (top; horizontal axis - time, sec). Autocorrelation functions of a series of 10 emitted sweep signals (bottom left; horizontal axis - time, sec), and their spectra (bottom right; horizontal frequency, $\mathrm{Hz}$ ). 
(a)

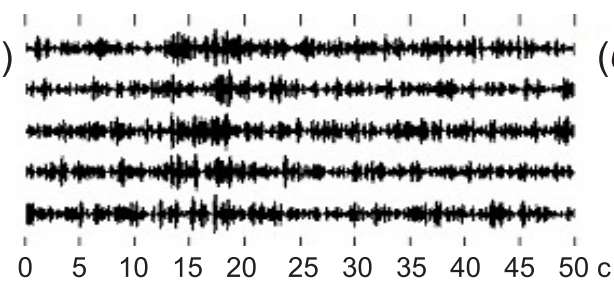

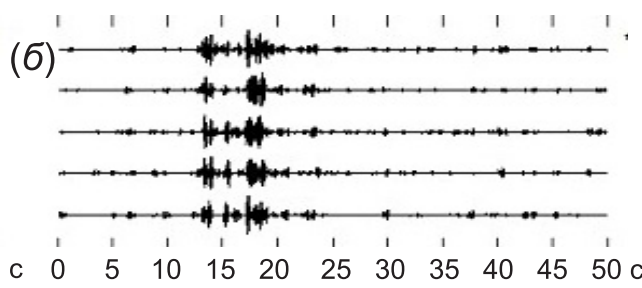

Рис. 7. Вибрационные сейсмограммы, зарегистрированные линейной сейсмической группой из пяти сейсмоприемников на расстоянии 351 км от источника ЦВО-100 на профиле Байкал - Улан-Батор. Исходные сейсмограммы - $(a)$, сейсмограммы после пространственной фильтрации - (б). По горизонтальной оси редуцированное время в секундах T=t-L/8, где t - время, c, L=351 км - расстояние от источника, скорость редукции 8 км/c.

Fig. 7. Vibration seismograms recorded by a linear seismic group of five seismic receivers at a distance of $351 \mathrm{~km}$ from the CVO-100 source on the Baikal-Ulaanbaatar profile. (a) Initial seismograms; (6) seismograms after spatial filtering. Horizontal axis - reduced travel time $\mathrm{T}=\mathrm{t}-\mathrm{L} / 8$, where $\mathrm{t}$ is travel time (sec), $\mathrm{L}$ is distance from the source $(351 \mathrm{~km})$, and the reduction velocity is $8 \mathrm{~km} / \mathrm{sec}$.

линейной группы составляла 1-2 км. Эти эксперименты были выполнены ИВМиМГ СО РАН и ГИН СО РАН (Россия) совместно с ИАГ МАН (Монголия).

Обработка вибросейсмических сигналов, зарегистрированных малыми сейсмическими группами, производилась с использованием алгоритмов пространственной фильтрации данных сейсмической группы, которые оказались очень эффективными для выделения основных групп волн (сейсмических фаз) и подавления волн-помех. На рис. 7 приведен пример пространственной фильтрации сейсмограмм, полученных для линейной сейсмической группы из пяти сейсмоприемников с общей базой 0.8 км в точке регистрации на расстоянии 351 км от источника ЦВО-100 на профиле Байкал - УланБатор.

Особенностью вибрационных сейсмограмм является то, что временам вступлений волн соответствуют максимумы в группах колебаний, поэтому для визуализации и анализа вибрационных сейсмограмм применялось преобразование Гильберта и графические средства отображения текущих амплитуд сейсмограмм (рис. 8). Вибрационные сейсмограммы от источника ЦВО-100 были получены во всех точках 500-километрового профиля на удалениях от 65 до 500 км от источника. Они приведены на рис. 8 для расстояний 205, 241, 294, 351 и 377 км от вибратора ЦВО-100. Графическое отображение текущих амплитуд сейсмограмм после преобразования Гильберта позволило идентифицировать на вибрационных сейсмограммах отдельные волны в группе Р-волн и определить времена их вступлений.

Времена вступлений первых четырех волн в группе Р-волн на вибрационных сейсмограммах использовались в качестве экспериментальных данных для сравнения с теоретическими сейсмограммами для скоростных моделей экспериментов BEST и PASSCAL. На рис. 9 приведены редуцирован- ные теоретические сейсмограммы для математических скоростных моделей экспериментов BEST и PASSCAL, а также экспериментальные данные времен вступлений Р-волн в отдельных точках 400-километрового участка профиля Байкал - УланБатор.

\section{5. ОБСУЖДЕНИЕ РЕЗУЛЬТАТОВ}

Сравнение теоретических сейсмограмм для математических моделей экспериментов BEST и PASSCAL с экспериментальными данными (рис. 9) показывает, что времена вступлений Р-волн на экспериментальных вибрационных сейсмограммах на 400-километровом участке профиля Байкал - УланБатор находятся в области групп волн с максимальными амплитудами на теоретических сейсмограммах. В диапазоне расстояний от 65 до 205 км от источника теоретические и экспериментальные значения первых вступлений совпадают с точностью 0.2-0.4 с для скоростных моделей обоих экспериментов. Более существенные отличия теоретических и экспериментальных данных имеются в области расстояний 230-400 км от источника.

Для скоростной модели эксперимента BEST на расстояниях 230-400 км от источника экспериментальные значения первых вступлений близки к годографу волн со скоростью 6.7 км/с (см. рис. 4, волны 5). Вместе с тем на экспериментальных сейсмограммах отсутствуют волны, соответствующие волнам с кажущимися скоростями 7.35-7.46 км/с (см. рис. 4, волны 6). Это свидетельствует о том, что предположение о существовании в скоростной модели эксперимента BEST [Nielsen, Thybo, 2009] слоя в нижней коре со скоростями 7.2-7.3 км/с и мощностью более 10 км не находит экспериментального подтверждения. 
Расстояние от вибратора 205 км

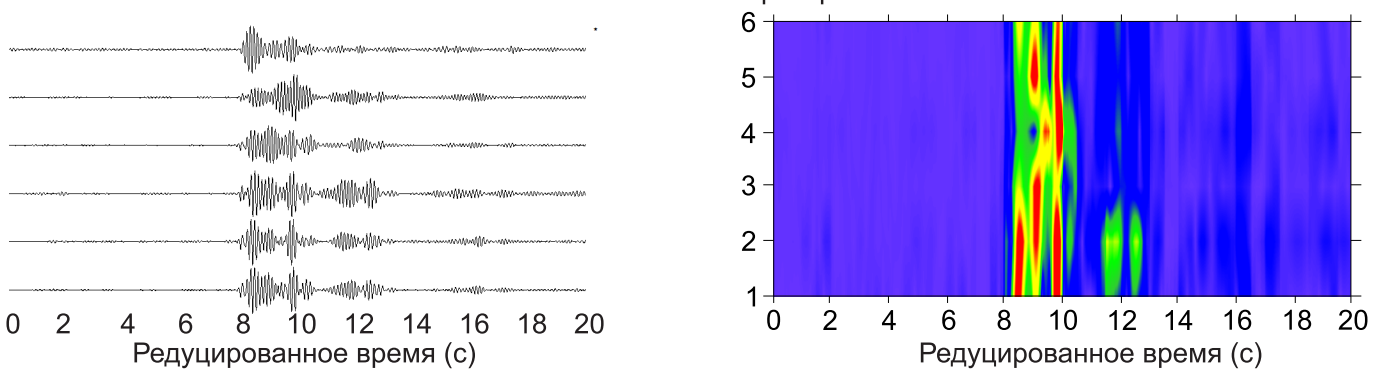

Расстояние от вибратора 241 км
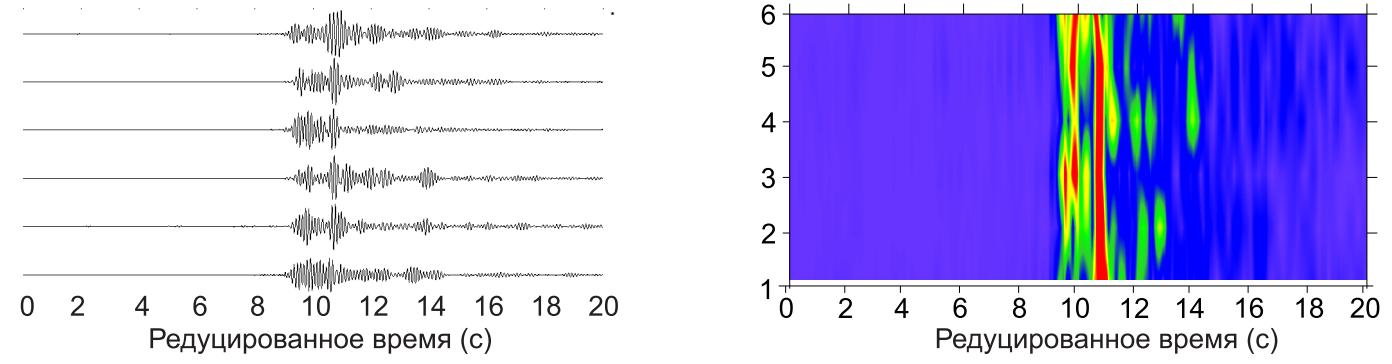

Расстояние от вибратора 294 км
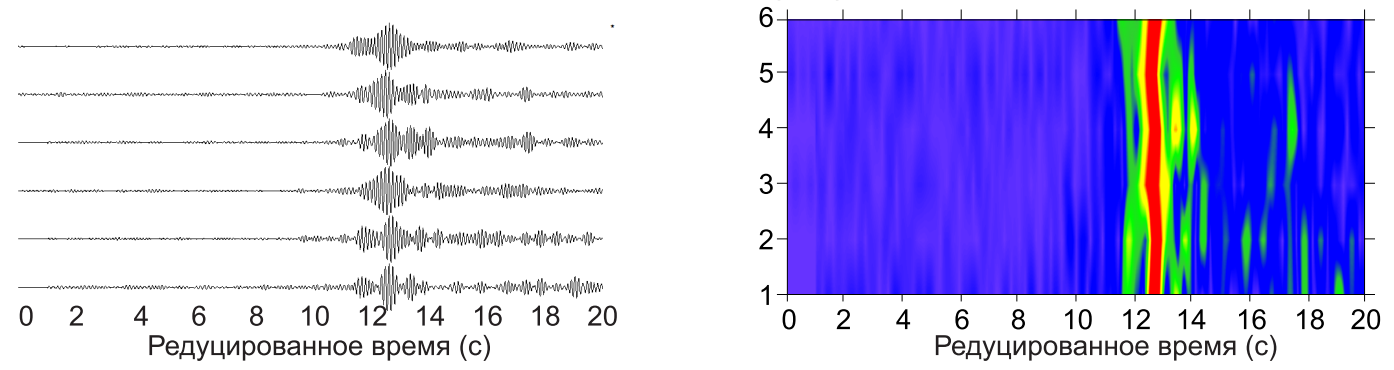

Расстояние от вибратора 351 км
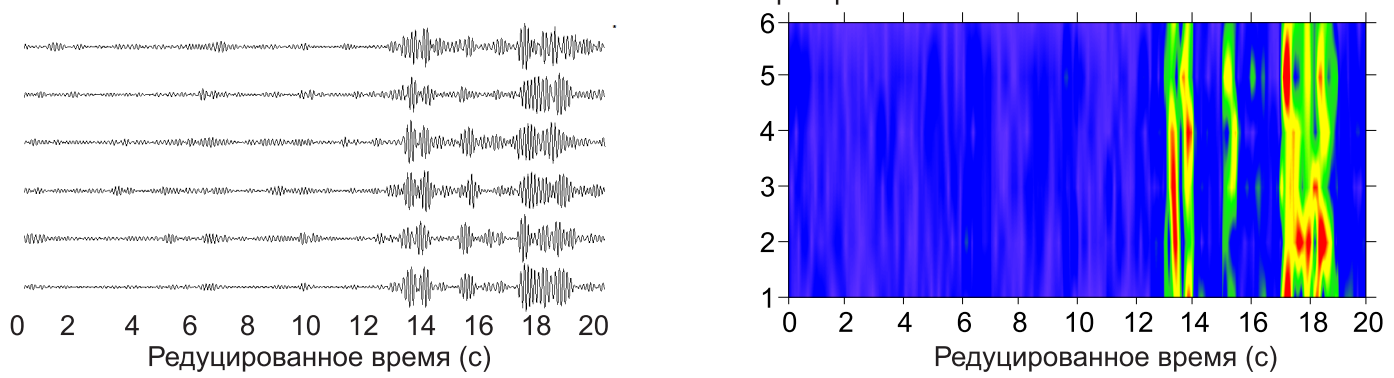

Расстояние от вибратора 377 км
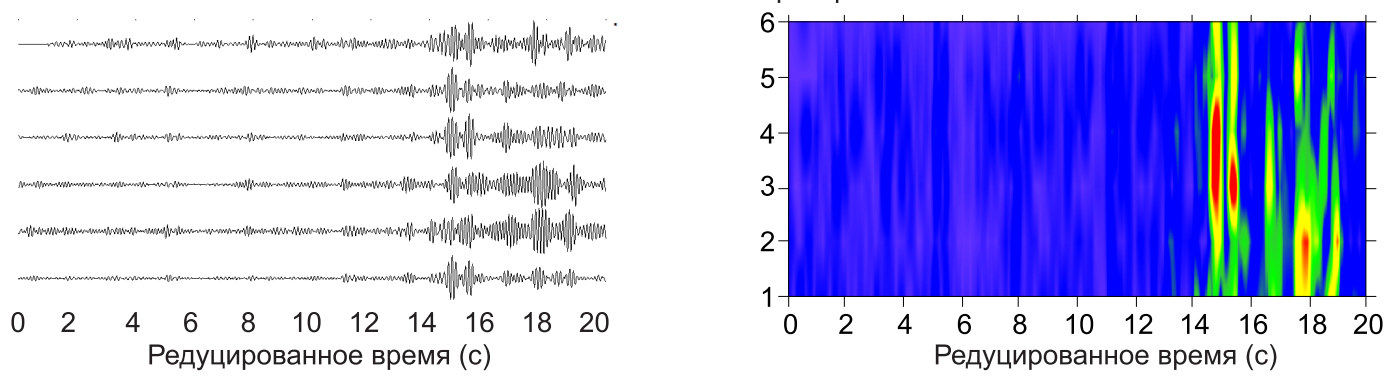

Рис. 8. Вибрационные сейсмограммы для 500-километрового профиля Байкал - Улан-Батор. Расстояние от источника ЦВО-100 - 205, 241, 294, 351 и 377 км. Графическое представление амплитуд в группе Р-волн с использованием преобразования Гильберта - справа, вибрационные сейсмограммы -слева. По вертикали - номер датчика, по горизонтали - редуцированное время в секундах $\mathrm{T}=\mathrm{t}-\mathrm{L} / 8$, где $\mathrm{t}$ - время, $\mathrm{L}$ - расстояние от источника, скорость редукции 8 км/с. Красный цвет соответствует максимумам амплитуды колебаний, синий цвет - минимумам.

Fig. 8. Vibration seismograms for the $500-\mathrm{km}$ long Baikal-Ulaanbaatar profile. Distances from the source: $205 \mathrm{~km}$, $241 \mathrm{~km}$, $294 \mathrm{~km}, 351 \mathrm{~km}$, and $377 \mathrm{~km}$. Right - graphs of amplitudes in the P-wave group using the Hilbert transformation. Left - vibration seismograms. Vertical axis - sensor number. Horizontal axis - reduced travel time $\mathrm{T}=\mathrm{t}-\mathrm{L} / 8$, where $\mathrm{t}$ is travel time $(\mathrm{sec}), \mathrm{L}$ is distance from the source $(\mathrm{km})$, and the reduction velocity is $8 \mathrm{~km} / \mathrm{sec}$. Colour codes of oscillation amplitudes: red - maximum, blue - minimum. 

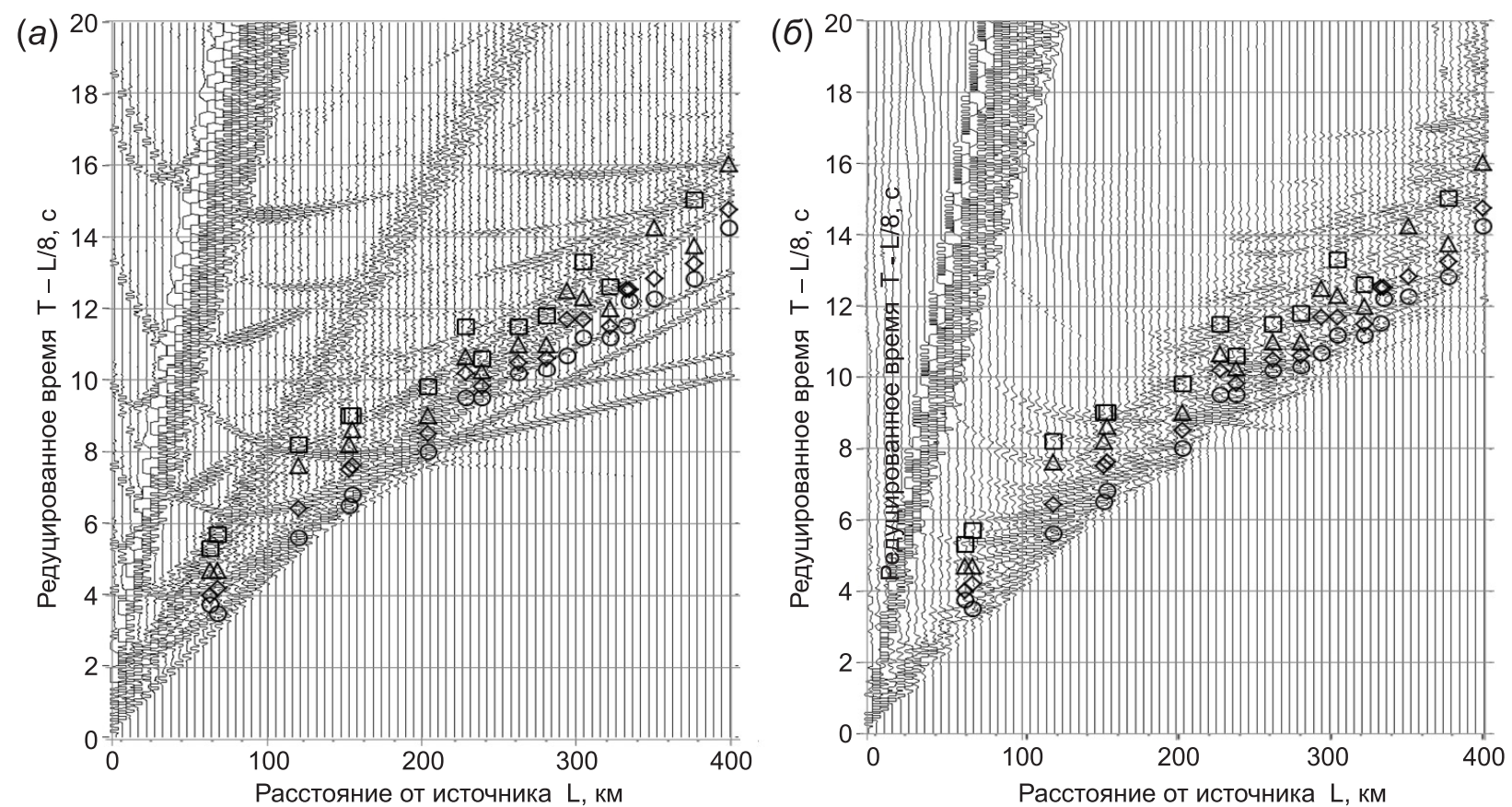

Рис. 9. Редуцированные теоретические сейсмограммы и экспериментальные данные времен вступлений Р-волн для 400-километрового участка профиля Байкал - Улан-Батор: (a) - для скоростной модели эксперимента ВEST, (б) - для эксперимента PASSCAL. Точки на графиках - времена вступлений первых четырех волн максимальной амплитуды в группе Р-волн на вибрационных сейсмограммах. По горизонтальной оси - расстояние L (км) от источника ЦВ0-100, по вертикальной оси - редуцированное время T=t-L/8, где $\mathrm{t}$ - время (c), L - расстояние от источника (км), скорость редукции 8 км/с.

Fig. 9. Reduced theoretical seismograms and experimental values of the P-wave arrival times for the 400-km long section of the Baikal - Ulaanbaatar profile. Velocity models of the crust based on the BEST and PASSCAL experiment data: (a) and (б), respectively. Dots on the graphs - arrival times of the first four waves with the maximum amplitude in the P-wave group on the vibration seismograms. Horizontal axis - distance L $(\mathrm{km})$ from the CVO-100 source. Vertical axis - reduced travel time $\mathrm{T}=\mathrm{t}-\mathrm{L} / 8$, where $\mathrm{t}$ is travel time ( $\mathrm{sec}), \mathrm{L}$ is distance from the source $(\mathrm{km})$, and the reduction velocity is $8 \mathrm{~km} / \mathrm{sec}$.

Для скоростной модели эксперимента PASSCAL экспериментальные значения времен вступлений поперечных волн на расстояниях 65-400 км от источника соответствуют первым волнам в группе волн большой амплитуды (см. рис. 4, группы 2, 3 и 4). Волны малой амплитуды на теоретических сейсмограммах, соответствующие первым вступлениям со скоростью $6.94 \mathrm{kм} / \mathrm{c}$ на расстояниях 230400 км от источника (см. рис. 4, группа 4), на вибрационных сейсмограммах находятся на уровне шумов и достоверно не выделяются. По этой же причине достоверно не выделяются на вибросейсмических сейсмограммах рефрагированные волны от верхней мантии со скоростями 8.2-8.3 км/с, присутствующие на теоретических сейсмограммах экспериментов BEST и PASSCAL (см. рис. 4, волны $7,5)$.

\section{6. ЗАКЛЮЧЕНИЕ}

Проведено сравнение теоретических сейсмограмм и данных о временах вступлений Р-волн на экспериментальных вибрационных сейсмограммах на 400-километровом участке профиля Байкал Улан-Батор. Теоретические сейсмограммы получены методами математического моделирования волновых полей для скоростных моделей земной коры экспериментов BEST и PASSCAL. Математическое моделирование выполнено с использованием алгоритмов и программ, разработанных сотрудниками ИВМиМГ СО РАН на суперкомпьютерах Сибирского вычислительного центра. Вибрационные сейсмограммы получены при измерении волнового поля вибратора ЦВО-100 Южнобайкальского полигона СО РАН.

Экспериментальные значения времен вступлений в группе Р-волн на вибрационных сейсмограммах соответствуют временам вступлений на теоретических сейсмограммах для наиболее интенсивных волн. Волны малой амплитуды в первых вступлениях выделены на экспериментальных вибрационных сейсмограммах не на всех расстояниях от источника.

Вибросейсмические сейсмограммы в различных точках профиля обладают высокой воспроизво- 
V.V. Kovalevsky et al.: Research and verification of the Earth's crust velocity models...

димостью благодаря высокой стабильности излучения вибратором свип-сигналов и применению малых сейсмических групп при регистрации вибросигналов. Это позволяет использовать накопление идентичных сеансов излучения для увеличения отношения сигнал/шум и осуществлять пространственную фильтрацию для выделения и идентификации волн. Такие качества делают мощный сейсмовибратор наиболее приемлемым источником для задач верификации скоростных моделей земной коры по сравнению с мощными взрывами.

По результатам выполненных исследований скоростных моделей земной коры экспериментов BEST и PASSCAL можно сделать вывод об эффективности применения методов математического моделирования и активной сейсмологии с мощными вибрационными источниками для исследования и верификации скоростных моделей земной коры и верхней мантии.

\section{7. БЛАГОДАРНОСТИ}

Авторы выражают признательность коллегам из Байкальского и Бурятского филиалов ФИЦ ЕГС РАН, а также коллегам из ИАГ МАН за помощь в проведении вибросейсмических исследований и за ценные замечания при обсуждении результатов работ. Работа выполнена в рамках проекта 03152019-0003 госзадания ИВМиМГ СО РАН.

\section{8. ЛИТЕРАTУРА / REFERENCES}

Alekseev A.S., Chichinin I.S., Korneev V.A., 2005. Powerful low-frequency vibrators for active seismology. Bulletin of the Seismological Society of America 95 (1), 1-17. https://doi.org/10.1785/0120030261.

Alekseev A.S., Glinsky B.M., Kovalevsky V.V., Mikhailenko B.G., 1997. Problems of active seismology. In: K. Fuch (Ed.), Upper mantle heterogeneities from active and passive seismology. Nato ASI Series, vol. 17, p. 123-130.

Ammon C.J., Randall G.E., Zandt G., 1990. On the nonuniqueness of receiver function inversions. Journal of Geophysical Research: Solid Earth 95 (B10), 15303-15318. https://doi.org/10.1029/JB095iB10p15303.

Burdick L.J., Langston C.A., 1977. Modeling crustal structure through the use of converted phases in teleseismic bodywave forms. Bulletin of the Seismological Society of America 67 (3), 677-691.

Fatyanov A.G., 1990. Semi-analytical method for solving direct dynamic problems in layered media. Doklady AN SSSR 310 (2), 323-327 (in Russian) [Фатьянов А.Г. Полуаналитический метод решения прямых динамических задач в слоистых средах // Доклады АН СССР. 1990. Т. 310. № 2. С. 323-327].

Fatyanov A.G., Terekhov A.V., 2011. High-performance modeling acoustic and elastic waves using the parallel Dichotomy Algorithm. Journal of Computational Physics 230 (5), 1992-2003. https://doi.org/10.1016/j.jcp.2010.11.046.

Gao S.S., Liu K.H., Chen C., 2004. Significant crustal thinning beneath the Baikal rift zone: New constraints from receiver function analysis. Geophysical Research Letters 31 (20), L20610. https://doi.org/10.1029/2004GL020813.

Karavaev D.A., 2009. Parallel implementation of wave field numerical modeling method in 3D models of inhomogeneous media. Vestnik of Lobachevsky University of Nizhni Novgorod (6(1)), 203-209 (in Russian) [Караваев Д.А. Параллельная реализация метода численного моделирования волновых полей в трехмерных моделях неоднородных сред // Вестник Нижегородского университета им. Н.И. Лобачевского. 2009. № 6 (1). С. 203-209].

Karavaev D., Glinsky B., Kovalevsky V., 2015. A technology of 3D elastic wave propagation simulation using hybrid supercomputers. In: CEUR workshop proceedings of the 1st Russian conference on supercomputing. (Supercomputing Days Moscow, Russia, September 28-29). Moscow, p. 26-33.

Kosarev G.L., Petersen N.V., Vinnik L.P., Roecker S.W., 1993. Receiver functions for the Tien Shan analog broadband network: Contrasts in the evolution of structures across the Talasso-Fergana fault. Journal of Geophysical Research: Solid Earth 98 (B3), 4437-4448. https://doi.org/10.1029/92JB02651.

Kovalevskiy V., Chimed O., Tubanov Ts., Braginskaya L., Grigoruk A., Fatyanov A., 2017. Vibroseismic sounding of the Earth's crust on the profile Baikal-Ulaanbaatar. In: Proceedings of the International conference on astronomy \& geophysics. Ulaanbaatar, p. 261-265.

Kovalevsky V.V., Braginskaya L.P., Grigoryuk A.P., 2016a. An information technology of verification of Earth's crust velocity models. In: 13th International Scientific-Technical Conference APEIE 2016 Proceedings, Vol. 2, p. 443-446.

Kovalevsky V.V., Fatyanov A.G., Karavayev D.A., 2016b. Verification of the velocity models of the Earth's crust of the Baikal region, built according to the BEST and PASSCAL experiments. Interexpo Geo-Siberia 4 (2), 3-7 (in Russian) [Ковалевский В.В., Фатьянов А.Г., Караваев Д.А. Верификация скоростных моделей земной коры Байкальского региона, построенных по данным экспериментов BEST и PASSCAL // Интерэкспо Гео-Сибирь. 2016. T. 4. № 2. C. 3-7].

Krylov S.V., Golenetsky S.I., Petrik G.V., 1974. Harmonization of seismology and PSS data on the structure of the upper mantle in the Baikal rift zone. Geologiya i Geofizika (Russian Geology and Geophysics) 15 (12), 61-65 (in Russian) [Крылов С.В., Голенецкий С.И., Петрик Г.В. Согласование данных сейсмологии и ГСЗ о строении верхов мантии в Байкальской рифтовой зоне // Геология и геофизика. 1974. Т. 15. № 12. С. 61-65]. 
Mishen'kin B.P., Mishen'kina Z.R., Petrik G.V., Shelud'ko I.F., Mandel'baum M.M., Seleznev V.S., Solov'ev V.M., 1999. Deep seismic sounding of the Earth's crust and upper mantle in the Baikal rift zone. Izvestiya, Physics of the Solid Earth 35 (7-8), 594-611.

Mordvinova V.V., Artemyev A.A., 2010. The three-dimensional shear velocity structure of lithosphere in the southern Baikal rift system and its surroundings. Russian Geology and Geophysics 51 (6), 694-707. https://doi.org/10.1016/ j.rgg.2010.05.010.

Mordvinova V.V., Deschamps A., Dugarmaa T., Déverchère J., Ulziibat M., Sankov V.A., Artem'ev A.A., Perrot J., 2007. Velocity structure of the lithosphere on the 2003 Mongolian-Baikal transect from SV waves. Izvestiya, Physics of the Solid Earth 43 (2), 119-129. https://doi.org/10.1134/S1069351307020036.

Mordvinova V.V., Vinnik L.P., Kosarev G.L., Oreshin S.I., Treusov A.V., 2000. Teleseismic tomography of the Baikal rift lithosphere. Doklady Earth Sciences 372 (4), 716-720.

Mordvinova V.V., Zorin Yu.A., Gao Sh., Davis P.M., 1995. Estimates of the crustal thickness on the Irkutsk-UlanBator-Undurshil profile using spectral ratios of bulk seismic waves. Fizika Zemli (9), 35-42 (in Russian) [Mордвинова В.В., Зорин Ю.А., Гао Ш., Дэвис П.М. Оценки толщины земной коры на профиле Иркутск-Улан-БаторУндуршил по спектральным отношениям объемных сейсмических волн // Физика Земли. 1995. № 9. С. 35-42].

Nielsen C., Thybo H., 2009. Lower crustal intrusions beneath the southern Baikal rift zone: evidence from fullwaveform modelling of wide-angle seismic data. Tectonophysics 470 (3-4), 298-318. https://doi.org/10.1016/ j.tecto.2009.01.023.

Owens T.J., Zandt G., Taylor S.R., 1984. Seismic evidence for an ancient rift beneath the Cumberland Plateau, Tennessee: A detailed analysis of broadband teleseismic P waveforms. Journal of Geophysical Research: Solid Earth 89 (B9), 7783-7795. https://doi.org/10.1029/JB089iB09p07783.

Puzyrev N.N. (Ed.), 1981. Interior of Baikal from Seismic Data. Nauka, Novosibirsk, 105 p. (in Russian) [Hедра Байкала (по сейсмическим данным) / Ред. Н.Н. Пузырев. Новосибирск: Наука, 1981. 105 с.].

Puzyrev N.N., Mandelbaum M.M., Krylov S.V., Mishenkin B.P., Krupskaya G.V., Petrick G.V., 1973. Deep seismic investigations in the Baikal rift zone. Tectonophysics 20 (1-4), 85-95. https://doi.org/10.1016/0040-1951(73)90098-X.

Puzyrev N.N., Mandelbaum M.M., Krylov S.V., Mishenkin B.P., Petrik G.V., Krupskaya G.V., 1978. Deep structure of the Baikal and other continental rift zones from seismic data. Tectonophysics 45 (1), 15-22. https://doi.org/10.1016/ 0040-1951(78)90219-6.

Seleznev V.S., Tibo G., Perchuk E., Emanov A.F., Suvorov V.D., Soloviov V.M., Tat'kov G.I., Liseikin A.V., Annenkov V.V., Mishen'kina Z.R., 2003. Using the new deep seismic technology to study the deep structure of the southwestern flank of the Baikal rift zone. In: Problems of seismology in the third millennium. Proceedings of the International Geophysical Conference (15-19 September 2003, Novosibirsk). Publishing House of SB RAS, Novosibirsk, p. 324-329 (in Russian) [Селезнев В.С., Тибо Г., Перчук Э., Еманов А.Ф., Суворов В.Д., Соловьев В.М., Татьков Г.И., Лисейкин А.В., Анненков В.В., Мишенькина З.Р. Использование новой технологии глубинных сейсмических исследований при изучении глубинного строения юго-западного фланга Байкальской рифтовой зоны // Проблемы сейсмологии III тысячелетия: Материалы международной геофизической конференции (15-19 сентября 2003 г., г. Новосибирск). Новосибирск: Изд-во СО РАН, 2003. С. 324-329].

Suvorov V.D., Mishenkina Z.M., Petrick G.V., Sheludko I.F., Seleznev V.S., Solovyov V.M., 2002. Structure of the crust in the Baikal rift zone and adjacent areas from deep seismic sounding data. Tectonophysics 351 (1-2), 61-74. https:// doi.org/10.1016/S0040-1951(02)00125-7.

Tat'kov G.I., Tubanov Ts.A., Bazarov A.D., Tolochko V.V., Kovalevsky V.V., Braginskaya L.P., Grigoruk A.P., 2013. Vibroseismic studies of the lithosphere of the Baikal rift zone and adjacent territories. Otechestvennaya Geologiya (Russian Geology) (3), 16-23 (in Russian) [Татьков Г.И., Тубанов Ц.А., Базаров А.Д., Толочко В.В., Ковалевский В.В., Брагинская Л.П., Григорюк А.П. Вибросейсмические исследования литосферы Байкальской рифтовой зоны и сопредельных территорий // Отечественная геология. 2013. № 3. С. 16-23].

Ten Brink U.S., Taylor M.H., 2002. Crustal structure of central Lake Baikal: Insights into intracontinental rifting. Journal of Geophysical Research: Solid Earth 107 (B7), 2132. https://doi.org/10.1029/2001JB000300.

Tsibulchik G.M. (Ed.), 2004. Active Seismology with Powerful Vibrational Sources. Publishing House of SB RAS, Geo Branch, Novosibirsk, 387 p. (in Russian) [Активная сейсмология с мощными вибрационными источниками / Ред. Г.М. Цибульчик. Новосибирск: Изд-во СО РАН, филиал «Гео», 2004. 387 с.].

Vinnik L.P., 1977. Detection of waves converted from P to SV in the mantle. Physics of the Earth and Planetary Interiors 15 (1), 39-45. https://doi.org/10.1016/0031-9201(77)90008-5.

Zhao D., Lei J., Inoue T., Yamada A., Gao S.S., 2006. Deep structure and origin of the Baikal rift zone. Earth and Planetary Science Letters 243 (3-4), 681-691. https://doi.org/10.1016/j.epsl.2006.01.033.

Zorin Y.A., Kozhevnikov V.M., Novoselova M.R., Turutanov E.K., 1989. Thickness of the lithosphere beneath the Baikal rift zone and adjacent regions. Tectonophysics 168 (4), 327-337. https://doi.org/10.1016/0040-1951(89)90226-6.

Zorin Y.A., Mordvinova V.V., Turutanov E.K., Belichenko B.G., Artemyev A.A., Kosarev G.L., Gao S.S., 2002. Low seismic velocity layers in the Earth's crust beneath Eastern Siberia (Russia) and Central Mongolia: receiver function data and their possible geological implication. Tectonophysics 359 (3-4), 307-327. https://doi.org/10.1016/S00401951(02)00531-0. 
V.V. Kovalevsky et al.: Research and verification of the Earth's crust velocity models...

Zorin Y.A., Turutanov E.K., Mordvinova V.V., Kozhevnikov V.M., Yanovskaya T.B., Treussov A.V., 2003. The Baikal rift zone: the effect of mantle plumes on older structure. Tectonophysics 371 (1-4), 153-173. https://doi.org/10.1016/ S0040-1951(03)00214-2.

\section{CВEДЕНИЯ ОБ АВTOPAX | INFORMATION ABOUT AUTHORS}

\section{Валерий Викторович Ковалевский}

докт. техн. наук, заместитель директора по научной работе

Институт вычислительной математики

и математической геофизики СО РАН

630090, Новосибирск, проспект академика Лаврентьева, 6, Россия

凶e-mail: kovalevsky@sscc.ru

Алексей Геннадьевич Фатьянов

докт. физ.-мат. наук, г.н.с.

Институт вычислительной математики

и математической геофизики СО РАН

630090, Новосибирск, проспект академика Лаврентьева, 6, Россия

e-mail: fat@nmsf.sscc.ru

\section{Дмитрий Алексеевич Караваев}

канд. физ.-мат. наук, н.с.

Институт вычислительной математики

и математической геофизики СО РАН

630090, Новосибирск, проспект академика Лаврентьева, 6, Россия

e-mail: kda@opg.sscc.ru

\section{Людмила Петровна Брагинская}

ведущий программист

Институт вычислительной математики

и математической геофизики СО РАН

630090, Новосибирск, проспект академика Лаврентьева, 6, Россия

e-mail: ludmila@opg.sscc.ru

\section{Андрей Павлович Григорюк}

н.с.

Институт вычислительной математики

и математической геофизики СО РАН

630090, Новосибирск, проспект академика Лаврентьева, 6, Россия

e-mail: and@opg.sscc.ru

\section{Валентина Владимировна Мордвинова}

докт. геол.-мин. наук, в.н.с.

Институт земной коры СО РАН

664033, Иркутск, ул. Лермонтова, 128, Россия

e-mail: mordv@crust.irk.ru
Valery V. Kovalevsky

Doctor of Technical Sciences, Deputy Director for Science

Institute of Computational Mathematics and

Mathematical Geophysics, Siberian Branch of RAS

6 Academician Lavrentiev ave., Novosibirsk 630090, Russia

\section{Alexey G. Fatyanov}

Doctor of Physics and Mathematics, Chief Researcher

Institute of Computational Mathematics and

Mathematical Geophysics, Siberian Branch of RAS

6 Academician Lavrentiev ave., Novosibirsk 630090, Russia

\section{Dmitry A. Karavaev}

Candidate of Physics and Mathematics, Researcher

Institute of Computational Mathematics and

Mathematical Geophysics, Siberian Branch of RAS

6 Academician Lavrentiev ave., Novosibirsk 630090, Russia

\section{Lyudmila P. Braginskaya \\ Lead Programmer}

Institute of Computational Mathematics and

Mathematical Geophysics, Siberian Branch of RAS

6 Academician Lavrentiev ave., Novosibirsk 630090, Russia

\section{Andrey P. Grigoryuk}

Researcher

Institute of Computational Mathematics and

Mathematical Geophysics, Siberian Branch of RAS

6 Academician Lavrentiev ave., Novosibirsk 630090, Russia

\section{Valentina V. Mordvinova}

Doctor of Geology and Mineralogy, Lead Researcher

Institute of the Earth's Crust, Siberian Branch of RAS

128 Lermontov street, Irkutsk 664033, Russia 
Цырен Алексеевич Тубанов

канд. геол.-мин. наук, зав. лабораторией

Геологический институт СО РАН

670047, Улан-Удэ, ул. Сахьяновой, 6а, Россия

e-mail: geos@gin.bscnet.ru

Артем Дамбиевич Базаров

канд. геол.-мин. наук, н.с.

Геологический институт СО РАН

670047, Улан-Удэ, ул. Сахьяновой, 6а, Россия

e-mail: bazarov@ginst.ru

\section{Tsyren A. Tubanov}

Candidate of Geology and Mineralogy, Head of Laboratory

Geological Institute, Siberian Branch of RAS

6a Sakhyanova street, Ulan-Ude 670047, Russia

\section{Artem D. Bazarov}

Candidate of Geology and Mineralogy, Researcher

Geological Institute, Siberian Branch of RAS

6a Sakhyanova street, Ulan-Ude 670047, Russia 